\title{
EL GÓTICO NOMINALISTA Y LAS COPLAS DE JORGE MANRIQUE
}

El Gótico florido, que nosotros preferimos llamar Gótico nominalista por ser un reflejo del nominalismo de Guillermo de Occann ${ }^{1}$, que al negar la realidad de los universales afirma lo concreto e individual, causa del minucioso objetivismo de la pintura flamenca, y al sostener que la existencia de Dios, la creación del mundo y la inmortalidad del alma son verdades de fe, no demostrables por la razón, lleva al intuicionismo y al misticismo, raíces de la llamada devolio nova, cuyos ecos en las artes plásticas son el patetismo y la profusión en el decorado, hija de la efervescencia de la fantasía, puede explicarnos muchos aspectos de nuestra literatura del siglo xv. Fn el caso concreto de las Coplas de Jorge Manrique creemos que su unicidad nace en buena parte de la fusión del nominalismo con los primeros destellos del Renacimiento, que, aunque entre nosotros son perceptibles desde los tiempos de Juan II, se intensifican mucho en la época de los Reyes Católicos, a cuyo comienzo fueron escritas.

Se ha dicho que las Coplas no son otra cosa que una meditación sobre nuestro destino, en la que se nos incita a atender a lo eterno y a lo permanente y a desligarnos de lo transitorio con un exquisito dominio de la forma y sentido rítmico, ya que si por un lado los razonamientos nos commueven por lo lapidario de su expresión, por otro lado

1 E. Gilson, La philosophie au Moyen Age, París, I952, pp. 639-687. Véase también DANIEL-ROPS, L'Eglise de la Renaissance et de la Réforme, Paris, I957, p. I92: هL'art est de plus en plus réaliste, précis, art de l'individuel et du singulier, conme l'ockhanisme est aussi une philosophie de ce qui est: pour représenter un homme, un aninal, une plante, il se soucie de vérité beaucoup plus que ses prédécesseurs. De son temps, il a aussi le caractère pathétique, poussé à l'extrème dans les danses macabres qui se multiplient alors et qui exprime cette hantise de la mort qu'on a vue si lourde dans les conciences, mais qui se retrouve aussi bien daus les évocations, très nombreuses également, de la Passion du Christ ou de la Douleur de sa Mère, dans les Pietàs." 
el hábil manejo de las cadencias del pie quebrado produce el efecto, ya de la marcha de una procesión, ya del repique de una campana que tocara a muerto ${ }^{1}$. I, a perfecta adecuación de la musicalidad de las Coplas a su contenido fue ya notada por Ticknor ${ }^{2}$, Puymaigre ${ }^{3}$, Fitzmaurice-Kelly ${ }^{4}$, Cejador ${ }^{5}$, Teófilo Ortega ${ }^{6}$, Blecua $^{7}$ y Vittorio Borghini, quien nos dice que su metro "ci fa sentire, nella sua dura esattezza, qualcosa d'inesorabile, d'ineluttabile: onde le parole sembrano piantarsi nel quaternario conclusivo con soddezza di macigno 8 n. Pero no olvidemos que después de la meditación sobre nuestro destino el poeta nos presenta a su padre como el arquetipo del perfecto caballero cristiano, y que, aunque su idealizado retrato se encuentre al final y las enseñanzas que de su muerte se sacan estén al principio, tan sabio desorden no debe ocultarnos que el punto de partida del poema es la virtuosa muerte del maestre, hecho inmediato y particular del que Jorge Manrique se eleva al plano de lo universal, ni que las enseñanzas que aquí se nos dan se fundan en el ejemplo de su vida y muerte; lo que significa que ambos elementos, la admonición y el retrato de don Rodrigo, se equilibran y resultan en la estructura del poema igualmente importantes, pues si el poeta comienza con consideraciones que a todos afectan, éstas han nacido de un caso concreto, narrado con detenimiento al final del poema.

A muchos críticos han impresionado la serenidad y la falta de patetismo de las Coplas, la que tanto contrasta con el que impregna lo mismo las danzas de la muerte que la escultura funeraria francesa del xv,

1 E. Moreso Bádz, Antología de la poesía lirica española, Madrid, I952. p. XVII.

2 M. G. TICKNor, Historia de la Literatura española, traducida al castellano, con adiciones y notas críticas, por don P. DE GAYANGos y don E. DE VEDIA, Madrid, I85I, t. I, p. 435.

- COMTE DE Puymargre, La cour litteraire de D. Juan II, roi de Castille, Paris, I873, t. I, p. I04.

- J. Fitzalaurice-KeIIY, Historia de la literatura española, Madrid, I9I6, p. 92.

- J. CejAdor y FraUCA, Historia de la lengua y literatura castellana desde los origenes hasta Carlos V, Madrid, I9r5, p. 367.

- T. ORTEGA, La voz del paisaje, Burgos, I928, pp. 22-23.

- J. MI. BLECUA, Los grandes poetas del siglo XV, en Historia general de las litcraturas hispánicas, t. II, Barcelona, I95I, pp. $7 \mathrm{I}-\mathrm{I} 60$, y muy especialmente las I22-I 23 .

- V. Borghirt, Giorgio Manrique. La sua poesia e i suoi tempi, Génova, r952, p. 289. Véanse también L. SORRento, J. Manrique, Palermo, I94I; G. CanGIortr, Las Coplas di Manrique tra Medievo e Unanesimo, Bolonia, 1964; y A. DEL MONTE, Chiosa alle "Coplas» de Jorge Manrique, en Studi di Lengua e Letteratura Spagnola, Turtw, 1965, pp. 6r-79. 
en la que con frecuencia vemos al difunto en estado de putrefacción ${ }^{1}$. La atribución de tal serenidad a lo que suele llamarse estoicismo cristiano, difundido por el Petrarca y que tanto influye entre nosotros, refuerza nuestra tesis, pues tal estoicismo es un resultado de la fusión de la tradición cristiana de la Edad Media con el retorno a la antigüedad del Renacimiento. Tal falta de patetismo se hace muy visible en los versos en que el poeta roza por dos veces el tema de la danza de la muerte, sin que en ellos haya el menor asomo de la satisfacción con que los más humildes veían que la muerte igualaba a todos ':

Asst que no ay cosa fuerte,
que a papas y emperadores
$y$ perlados,
assi los trata la Muerte
como a los pobres pastores
de ganados... (estrofa I4).
Tantos duques excelentes.
tanlos marqueses y condes
$y$ varones
como vemos tan potentes,
di, Muerte, ¿do los escondes
$y$ traspones? (estrofa 23$)^{3}$.

-Fue Rosemarie Burkhart 4 la primera que señaló la existencia en las Coplas de tres partes: la meditación sobre la caducidad de la vida (estrofas I-I4), la versión manriqueña del viejo tema del Ubi sunt (estrofas I5-24) y el relato de la vida y muerte de don Rodrigo (estrofas 25-40). El que la segunda parte sea la transición necesaria entre el universalismo de la primera y el particularismo de la tercera no disminuye su importancia, subrayada por contener los versos más famosos del poema, pero lo uno y lo otro contribuyen a darle a esta parte un carácter similar a la de la punta de la ojiva en el arco gótico, que por ser el lugar en donde se cortan los dos segmentos de semicírculo que lo forman resulta lo más significativo, sin dejar de ser el sitio por el que se

1 E. MÂle, L'Art religieux de la fin du Moyen Age en France, París, Igo8, pp. $375-383$ y $468-469$.

2 La danza de la muerte puede verse en Rivadeneyra, t. LVII, pp. 379-385, - en M. Mentendez x PELAyo, Anlologia de poetas liricos castellanos, t. II, Madrid, I912, pp. I-25.

3 Todas las citas de las Coplas de este trabajo siguen el texto critico de FourCht:-Delbosc, reproducido en su Cancionero castellano del siglo $X V$, Madrid, 19I5, t. II, pp. $228^{a}-234^{a}$, aunque regularizando el uso de la $u$ y la $v$, de la $j$, la $i$ y la $y$, y de la $r$ y la $r r$.

- R. BURKIIART, Leben, Tod und Jenseits bei Mamrique und Villon, en Kölner Romanistische Arbeiten, t. I, Marburgo, I93I. 
pasa de un lado a otro, como aquí de lo discursivo a lo ponderativo. Con razón hablaba Salaverría de las líneas góticas de las Coplas, aunque reconociendo la presencia de ciertos elementos renacentistas ${ }^{1}$.

Lo que primero llama la atención del lector de las Coplas es la estructura fuertemente dialéctica de su primera parte, en la que tanto abundan los nexos lógicos: pues ${ }^{2}$, mas ${ }^{3}$, porque ${ }^{4}$, si $^{5}$, aun ${ }^{6}$, pero digo ?, por esso ${ }^{8}$, qué son sino ${ }^{9}$, desque ${ }^{10}$... A la severidad sintáctica de su dibujo contribuyen la falta de adjetivos calificativos ${ }^{11}$, que tienen en el lenguaje la misma función que el color en la pintura; el tono didáctico de la primera persona del plural con que el poeta se esfuerza por asociar al lector a su meditación ${ }^{12}$, y la segunda persona, también plural, con que le interpela, apelando a su testimonio ${ }^{13}$. El mismo valor apelativo tienen las tres interrogaciones que hay en esta parte ${ }^{14}$, en la que sistemáticamente se emplea el presente para expresar la intemporalidad de lo que se afirma. Lo mismo cabría decir de las exclamaciones, nacidas, no de la exaltación de los sentimientos, sino del desco de elevar el tono para impresionar aún más profundamente ${ }^{15}$. Lindando con lo escolástico están las estrofas $9 .^{a}$, IO. ${ }^{a}$ y II.a, en las que se demuestra lo perecedero de la hermosura y de la lozanía, de la nobleza y de aquellos bienes que por ser de fortuna tienen que pasar necesariamente de unos a otros, razonamientos que amplifican y desarrollan lo sintetizado en la estrofa anterior y que van seguidos por la afirmación de que, aunque nos acompañen hasta la muerte, su carácter perecedero contrasta mucho con la eternidad de los castigos infernales. También contribuye al tono didáctico la bipartición, a veces antitética, de las estrofas, y el paralelismo de muchos versos que repiten la misma idea que el anterior, expresada de distinto modo:

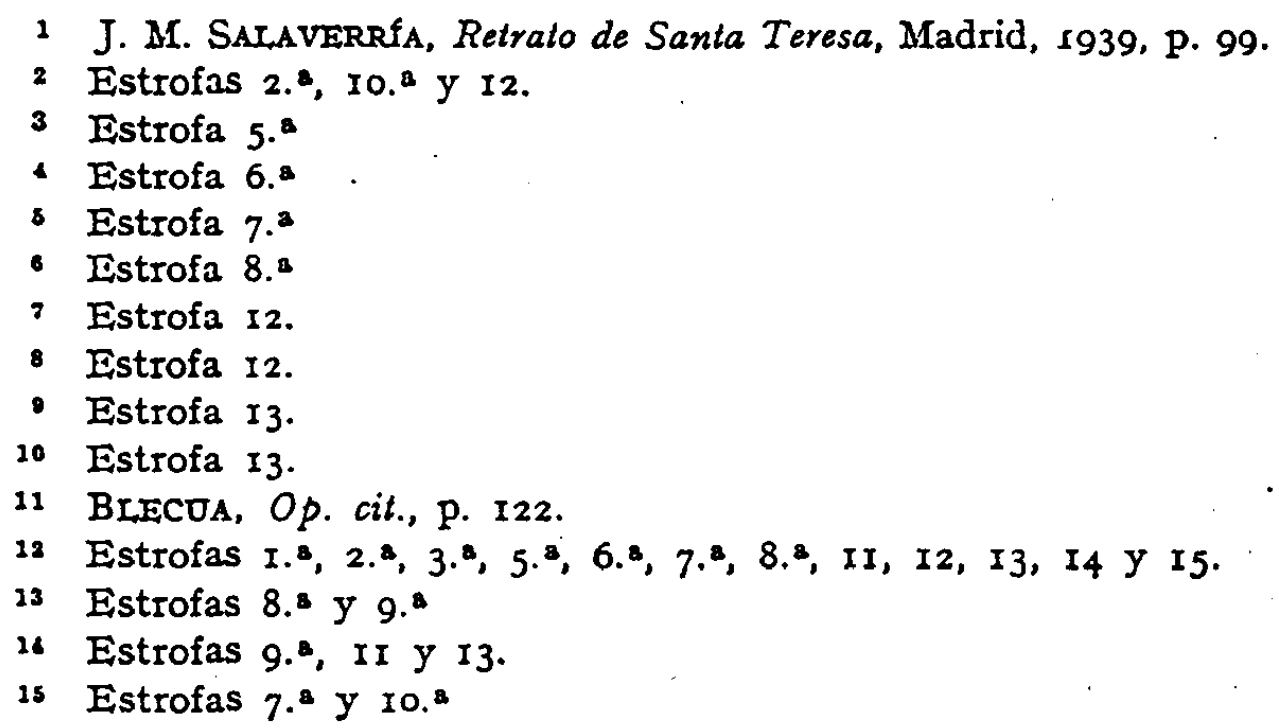




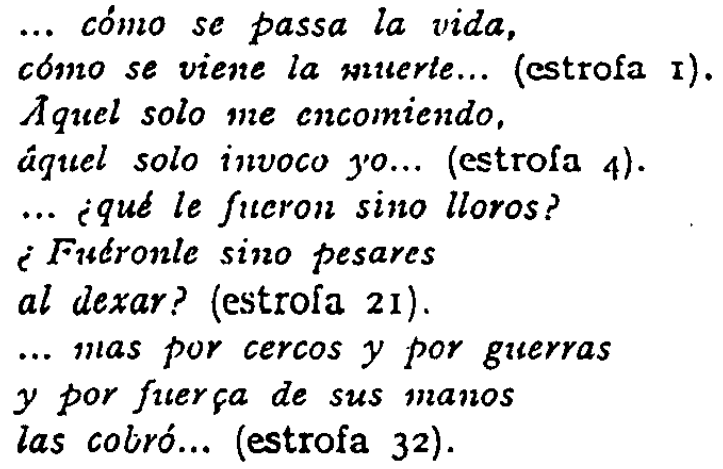

La anáfora o repetición de una palabra al comienzo de varios versos, por lo que tiene de reiterativo subraya mucho lo que hay en las Coplas de intención docente:

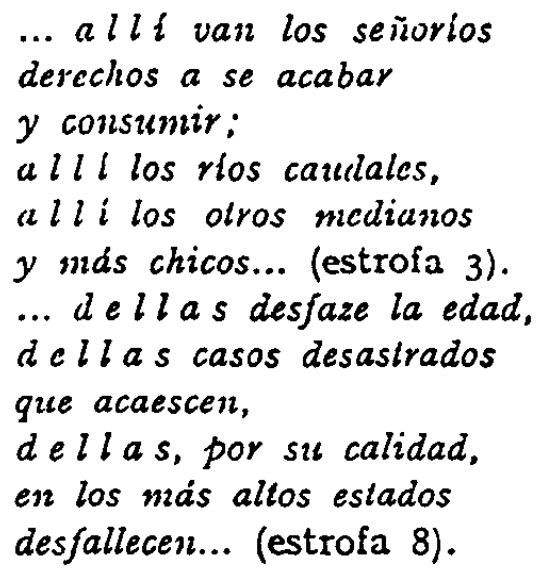

Creo que la invocación al Dios hecho hombre de la estrofa $4 .^{a}$ tiende a cimentar aún más sólidamente los pensamientos, aumentando con ello la sensación de firmeza y de serenidad en vez de la de arrebato y enajenamiento a que aspiraban los poetas antiguos al invocar a Apolo o a las musas.

Como Jorge Manrique es un poeta, no es extraño que su pensamiento plasme en imágenes, como la que compara nuestra vida con los ríos, que corren al mar ${ }^{1}$, o los placeres con los enemigos que huyen ante nosotros para hacernos caer en una emboscada, que es la muerte que nos acecha ${ }^{2}$. El que los antecedentes de la primera estén en el Eclesiastés $(I, 7)$ y los de la segunda en la terminación por Gómez Manrique del debate de Juan de Mena entre la razón y la voluntad no disminuye su valor ${ }^{3}$, pues lo importante no son las fuentes, sino el que el poeta vaya

1 Estrofa 3.a

2 Estrofa I3.

3 J. Manrique, Cancionero, ed. de A. Cortuna, Madrid, I94 I, p. XIIX y LII. 
de lo abstracto a lo concreto, de las verdades universales que forman la trama de su meditación a las comparaciones que nos las presentan plásticamente, aunque sin ocultar en ningún momento la línea dialéctica del pensamiento, del mismo modo que en la arquitectura gótica el decorado nunca oculta el funcionalismo de la estructura, tan coherente y lógica ${ }^{2}$.

Al llegar a lo alto de la ojiva y encontrar el tema del Ubi sunt, que se remonta a Boecio y que fue remozado por Guillermo de Morlay y en el que se agregaron, con el paso del tiempo, a las figuras más egregias del Antiguo Testamento, las más egregias de la antigüedad y luego los paladines más celebrados de la Edad Media, lo que nos sorprende no es la adición de nombres nuevos, como ya se hace en los Triunfos del Petrarca ${ }^{2}$, sino el que, renunciando al pasado remoto, se limite Manrique a lo inmediato y enumere solo a quienes muchos de sus lectores podfan haber visto. $Y$ ello de una manera deliberada, como si desdeñase a los que, por haberse convertido en flatus vocis, hubieran quedado desprovistos de realidad:

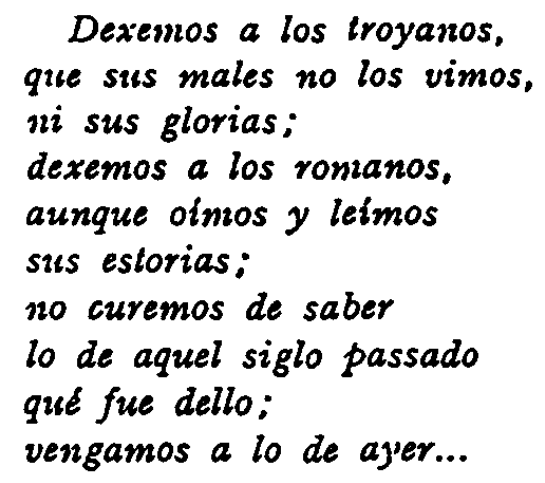

Es verdad que a renglón seguido afirma el poeta, siguiendo el hilo de su pensamiento:

... que también es olvidado como aquello... (estrofa I5).

Pero resulta evidente que a pesar de lo que aquí se dice, don Juan II, los infantes de Aragón, don Enrique IV, su hermano don Alfonso, proclamado rey tras la farsa de Avila, don Alvaro de Luna y los dos hermanos, don Juan Pacheco y don Pedro Girón, maestres de Santiago y de Calatrava, tienen para el poeta la realidad de lo percibido por los sentidos. Hay un momento en que incluso se deja transparentar esto: cuando,

1 E. PanofsKx, Gothic Architecture and Scholasticisin, Loudres, I957.

- Trionfo d'amore, III y IV, y Trionfo della fama, II. 
sobreponiéndose al odio de los Manrique por el condestable, dice, entre desdeñoso, digno y severo:

$$
\begin{aligned}
& \text {... no cumple que del se fable, } \\
& \text { sino solo } q u \text { e lo } v i \text { m os } \\
& \text { degollado... (estrofa 21). }
\end{aligned}
$$

Se trata de una percepción directa y concreta, de algo que muchos de sus contemporáneos presenciaron en la Plaza del Ochavo de Valladolid. Con razón decía Petriconi que esta evocación de Jorge Manrique ', con la que compara la de Villon en su balada de los caballeros, en la que no se limita, como en la de las damas, a incluir, tras una lista de famosas mujeres del pasado, a Juana de Arco, muerta treinta años antes de escribirse el poema, sino que enumera, a veces con mucha imprecisión, a quienes, fuera de Lanzarote, muchos de sus lectores podían haber visto, "lleva el tema del 'Ubi sunt' de la esfera de la reflexión a la de la experiencia inmediata" ${ }^{2}$, lo que, según él, es comparable a la sustitución, en el teatro del xvirr, de los trajes intemporales por los de época. Para terminar, ante tal coincidencia, con la afirmación, en que la verdad es vislumbrada, pero no alcanzada, de que "para distinguir esta voluntad artística común, este estilo de la declinante Edad Media, para circunscribirlo y presentarlo en su unicidad, tendría también que tomar primero ante nuestros ojos un significado, un carácter general y finalmente válidò' ${ }^{3}$.

Creo que solo el nominalismo, por lo que tiene de exaltación de la realidad de lo sensible, puede dar a la evocación de los más famosos del ayer inmediato tal significado. Fijémonos en que no solo es Villon quien coincide con Jorge Manrique, sino que, en la Castilla anterior a él, también coincide Ferrant Sánchez Calavera en su Dezir a la muerte de Ruy Diaz de Mendoza, donde, después de hablar en general de todos los estados, limítase a dar solo dos nombres de contemporáneos:

\section{El duque de Cabra e el Almirante $e$ otros muy grandes asas de Castilla...}

I H. PETruconI, Villons Ballade und Manriques Coplas, en Zeitschrift für französische Sprache und Literatur, Band LIX, Heft 5.6, pp. 343-360.

2 "... das "Ubi sunt" aus dem Bereich der Reflexion in den eines gegenwärtigen Erlebnisse bringt..." (Op. cit., p. 354.)

3 Diesen gemeinsamen Kunstwillen, diesen «Stil des ausgehenden MLittelalters" $z u$ erkennen, zu umschreiben und in seiner Eimmaligkeit darzustellen, würde auch in unseren Augen erst eine allgemein- und endgültige Lösung bedeu(Op. cit.; p. 360.)

- Cancionero de Juan Alfonso de Baena, ed. crítica por J. M. AzńceTs, Madrid, I966, t. III, p. I075. 
Se ha solido citar a Gómez Manrique como antecedente inmediato del Ubi sunt de su sobrino Jorge, pero la verdad es que aquél, en la Consolatoria a la condesa de Castro, su hermana, no deja de hacer su excursión por la antigüedad antes de llegar a dos testigos de la inestabilidad de la Fortuna

$$
\text { que fueron ayer, en nuestra nación...2 }
$$

y que son el infante don Enrique, hijo de S. Fernando, y don Alvaro de Luna, también mencionado en las Coplas para el señor Diego Arias de Avila, donde luego hallamos los nombres de tres figuras famosas de la antigüedad 2; 10 que significa que, entre nosotros, quien primero rompió con la tradición fue Sánchez Calavera y quien primero sacó todas las consecuencias que de ello podían sacarse fue nuestro poeta.

Después de la estrofa r6, la más famosa de todas las Coplas, en que Manrique se pregunta por el rey don Juan y por los infantes de Aragón, sus primos, uno de los cuales todavía vivía, y cuyo hondo lirismo nace en buena parte de que tales preguntas, que son como un eco remoto de las de Baruc, III, I6-I8 ${ }^{3}$, en este caso queden sin respuesta, nos encontramos con la estrofa en que se desdobla el alma del poeta, pues si por un lado su razón afirma la caducidad de lo que evoca, por otro lado sus sentidos son atraídos por lo evocado y hasta se dirfa que su corazón añora lo que rechaza su entendimiento:

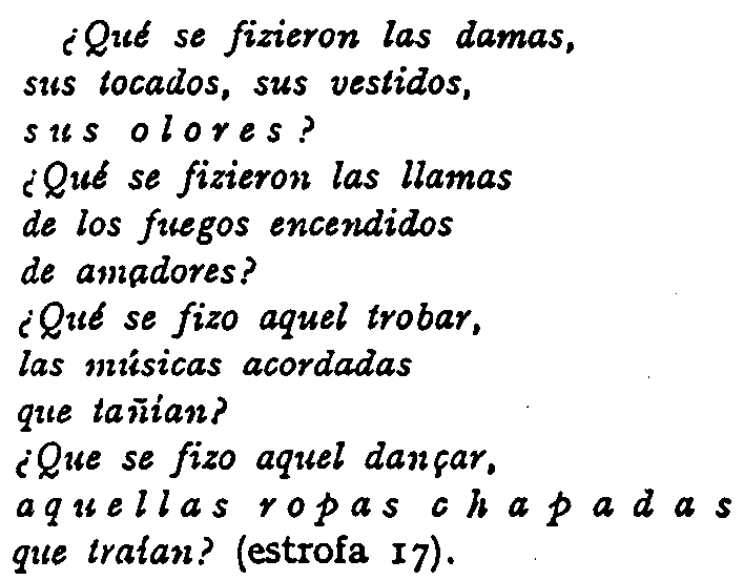

1 G. Alanrdeus, Cancionero, ed. de A. PAz y Mifin, Madrid, I885, t. I, p. 230.

2 G. ALANRIQUT, Op. cit., t. II, pp. 73-74 y 77 .

- Ubi sunt principes gentium, / et qui dominantur super bestias quae sunt super terram? / qui in avibus caeli ludunt, / qui argentum thesaurizant, et aurum, / in quo confidunt homines, / et non est finis acquisitionis eorum; /qui argentum fabricant et solliciti sunt, / nec est inventio operum eorum ? Sobre la historia del tema del Ubi sunt, desde el texto citado hasta el siglo XV, véanse las pp. 399-408 del t. XVIII de las Obras completas de M. Menéndez Y Perayo, Madrid, I944. 
Es muy curioso que Antonio Machado, aunque partiendo de supuestos muy distintos a los nuestros, captara con su fina intuición lo que hay aquí de realidad sensible e inmediata, única e irrepetible, de esa realidad que era precisamente la que exaltaba el nominalismo. Estas son sus palabras: «El poeta no pretende saber nada; pregunta por damas, tocados, vestidos, olores, llamas, amantes... El ¿qué se hicieron?, el devenir interrogante in $\mathrm{d}$ i vid u a 1 i $z$ a ya estas nociones genéricas, las coloca en el tiempo, en un pasado vivo, donde el poeta pretende intuirlas, como objetos únicos, las rememora o evoca. No pueden ser ya cualesquiera damas, tocados, fragancias y vestidos, sino aquellos que, estampados en la placa del tiempo, conmueven - itodavial- el corazón del poeta. Y 'aquel trovar', y' el 'danzar aquel' - a q u e 11 os y no otros- ¿qué se hicieron? insiste en preguntar el poeta, hasta llegar a la maravilla de la estrofa: 'aquellas ropas chapadas', vistas en los giros de una danza, las que traían los caballeros de Aragón -o quienes fueren-, y que surgen ahora en el recuerdo, como escapadas de un sueño, actualizando, mate $\mathrm{r}$ i a 1 i $z$ a n d o casi el pasado, en una trivial anécdota indumentaria. Terminada la estrofa, queda toda ella vibrando en nuestra memoria como una melodía única, que no podrá repetirse $\mathrm{ni}$ imitarse, porque para ello sería preciso haberla vividon ${ }^{\mathbf{1}}$.

\section{... aquellas ropas chapadas que traian...}

Creo que es una prueba de nuestra tesis la comparación de lo que dice Pedro Salinas al afirmar que a "las 'ropas chapadas' casi se las siente táctiles, con su pesada y suntuosa riqueza" ${ }^{2}$, con las siguientes palabras de René Huyghe, al describir la pintura de la misma época: "L'apparence visible des choses fut traduite dans sa complète veracité optique, avec un rendu égal de la matière et de la clarté qui la baigne. L'oeil devint roi, il arriva à suggérer le toucher» ${ }^{3}$. Recordemos cómo el deseo de producir sensaciones táctiles llevó a los pintores a representar en relieve las coronas, las empunaduras de las espadas y hasta los bordados en oro de las vestiduras, técnica que sobrevive curiosamente en la época barroca en la escuela del Cuzco. Otro ejemplo de sensación en que lo visual deriva hacia lo táctil son

$$
\text { las vaxillas tan febridas... }
$$

1 A. Machado, Obras completas, México, I940, p. 392.

2 P. 'SaInNAs, Jorge Manrique o tradición y originalidad, Buenos Aires, I947, p. I76.

- R. Huxghe, Sens et destin de l'art, Paris, 1967, t. II, p. 56. 
- tan bellamente cinceladas, seguidas, en la enumeración de las riquezas heredadas por el sucesor de don Juan II, por la mención de

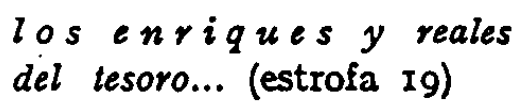

es decir, de las monedas acuñadas con la efigie de lós Trastámaras de este nombre, lo que prueba de nuevo el gusto por lo concreto e individual, pues se trata de monedas muy determinadas. Las imágenes de lo que hemos llamado punta de la ojiva y que son las

\section{... verduras}

de las eras?

de la estrofa $I 6$, los

$$
\text { de los prados? }
$$

de la I9, y, en la 24, la flecha, no guadaña, de la Muerte, que le permite pasar de claro todas las defensas que se le opongan, también nos traen, a pesar de las resonancias escriturarias de las dos primeras (Job, XIV, 2, y XV, 33, Salmos, XXXVI, 2, e Isaias, XI, 6, para las verduras, y Sapiencia, XI, 23, y Oscas, VI, 4, para los rocios) ${ }^{1}$, al plano de la experiencia directa del poeta, quien en sus andanzas por las llanuras castellanas tuvo que ver muchas veces las eras, tierra destinada para la trilla o cuadro de flores u hortalizas, quemadas por el sol del verano, - los rocios evaporarse al avanzar el día. También tuvo que ver en más de una ocasión a alguien caer atravesado por mortifera flecha, no por la alegórica guadaña. Muy curioso es el que cada una de estas imágenes esté encabaigada, como si el poeta quisiera que la pausa final del primer verso nos llevara a considerarlas más atentamente.

Aunque en la punta de la ojiva son evocadas ocho o nueve personas, pues no sabemos si los infantes de Aragón de que habla Manrique son don Juan, que fue rey de Navarra desde I425 y de Aragón desde $145^{8}$ y que

1 Qui quasi flos egreditur et conteritur, / et fugit velut umbra, et nunquam in eodem statu permanet, (Job, XIV, 2). Laedetur quasi vinea in primo flore botrus ejus, / et quasi oliva projiciens florem suum (Job, XV, 33). Quoniam tanquam foenum vclociter arescent, / et quemadmodum olera herbarum cito decident" (Salmos, XXXVI, 2). "Omnis caro foenum, / et omnis gloria ejus quasi flos agri (Isalas, $\mathrm{XL}, 6)$. Quoniam tanquam momentum staterae, / sic est ante te orbis terrarum, / et tanquam gutta roris antelucani quae descendit in terram (Sapiencia, XI, 23). * Misericordia vestra quasi nubes matutina, / et quasi ros mane pertransiens: (Oseas, VI, 4). 
murió en el mismo año que nuestro poeta, don Enrique, maestre de Santiago, y don Pedro, o los dos primeros, que en 1428 acompañaron por tierras de Castilla a su hermana doña Leonor, que las cruzaba para casarse con el heredero de Portugal 1 , el hecho es que solo los reyes castellanos están mencionados con sus nombres, como luego en la estrofa 25 don Rodrigo Manrique, lo que obedece al deseo de destacar a éste, a quien se nos presenta como arquetipo del perfecto caballero cristiano, lo que significa que en la última parte de las Coplas el nominalismo, aún visible en el gusto por lo concreto con que se sitúa la muerte del maestre

\section{en la su villa de Ocaña... (estrofa 33).}

es eclipsado por el platonismo, que, después de dominar en la época románica, domina de nuevo en el Renacimiento. Así, del mismo modo que el juglar del $M$ io $C i d$ recoge solo los episodios de la vida del héroe que le sirven para subrayar el carácter paradigmático que quiere darle, silenciando los años en que, tras su destierro, estuvo al servicio del rey moro de Zaragoza, tiempo cuyo transcurso solo percibimos al oír que se habla de casar a las niñas que quedaron en Cardeña en brazos de las doncellas de doña Jimena ${ }^{2}$, Jorge Manrique pone de relieve las luchas de su padre contra los moros y olvida que el rey de Granada le ayudó en sus guerras por el maestrazgo de Santiago, que quiso ocupar al ser elegido don Alvaro de Luna ilegalmente por no ser profeso ${ }^{3}$. Difícilmente el lector de las Coplas se dará cuenta, sin estudiar la biografía del conde de Paredes, de que los

$$
\begin{aligned}
& \text {... tratos tan onrosos } \\
& \text { que le dieron aitn mds tierra } \\
& \text { que tenta... (estrofa } 30 \text { ) }
\end{aligned}
$$

fueron los que en $x 452$ le llevaron a desistir de su pretensión a cambio del título de conde, quizás asustado de los daños que sus auxiliares moros podían causar a Castilla ; aún más difícilmente podrá adivinar

1 F. RICo, Unas coplas de Jorge Manrique y las fiestas de Valladolid en 1428 , en Anuario de Estudios Medievales, Barcelona, I965, pp. 515-524.

2 E. MORENo BAIZ, El estilo románico y el 'Cantar del Cid', en Actas del Segundo Congreso Internacional de Hispanistas, Nimega, I967, pp. 429-438.

- A. SerRano DE HARo, Personalidad y destino de Jorge Manrique, Madrid, r966, ’ेp. I72-173.

- Véanse en las pp. I4I-I42 del excelente libro de SERRANo DE Haro lo que dice de esto $A$. de Palencia. 
que los Manrique fueron partidarios de los infantes de Aragón, de uno de los cuales, que fue maestre de Santiago, recibió don Rodrigo su encomienda de Segura de la Sierra, la más importante de aquella orden, ni que luego siguieron al infante don Alfonso, alzado por rey en vida de su hermano, ni mucho menos que

$$
\begin{aligned}
& \text {... la dignidad } \\
& \text { de la gran cavallerta } \\
& \text { del Espada... (estrofa 3I) }
\end{aligned}
$$

que es como llama el poeta al maestrazgo de Santiago, para el que su padre fue canónicamente elegido en Uclés el año de la muerte de Enrique IV, mientras los caballeros leoneses se dividían entre don Alonso de Cárdenas y don Diego de Alvarado, nunca le fue confirmado por los Reyes Católicos, a quien apoyó contra los partidarios de la Beltraneja, que son los tiranos de la estrofa 32, en que se los reduce al papel de auxiliares de su defensor el rey de Portugal, como si Jorge Manrique no quisiera reconocer que aquella guerra, en la que él mismo encontraría la muerte, era una guerra fratricida y civil y no la virtuosa y magnifica cantada por Mena ${ }^{1}$ :

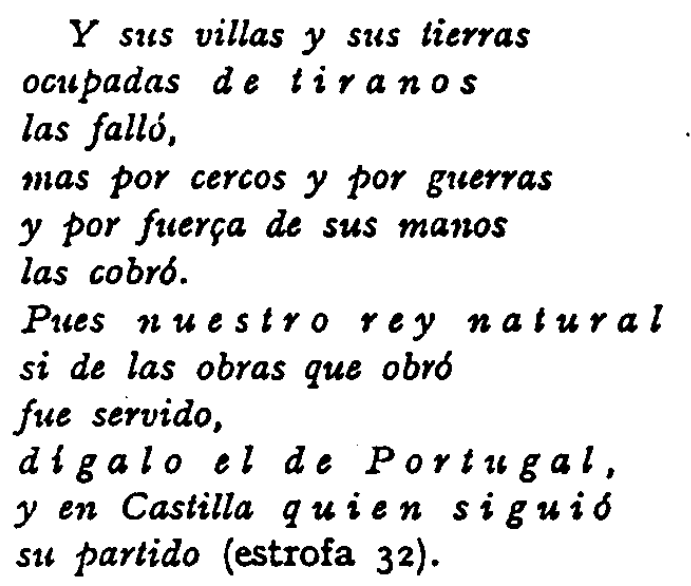

El convertir a los defensores de la excelente señora, que es como llamaron a la Beltraneja sus contemporáneos, en partidarios de don A1fonso $\mathrm{V}$ el Africano, derrotado en Toro, es una excesiva simplificación, solo explicable por el deseo de idealizar al conde de Paredes, servidor de muestro rey natural; es decir, del legítimo y verdadero, como le llama, insistiendo sobre ello, más adelante ${ }^{2}$, como si quisiera echarle

1 J. DE Mena, El laberinto de Fortuna o las trescientas, ed. J. M. BLECUA, Madrid, r943. p. 83.

2 Estrofa 33 . 
en cara a don Fernando el que el nombre de su padre fuera borrado de la serie de los maestres de Santiago, al favorecer, muerto aquél, la candidatura de don Alonso de Cárdenas los soberanos ${ }^{1}$.

Al mismo deseo de exaltar al maestre, discutido en vida y negado luego, responden las ponderaciones con que comienza la tercera parte del poema, imitadas por García Lorca en la segunda de su Llanto por Ignacio Sánchez Mejias 2:

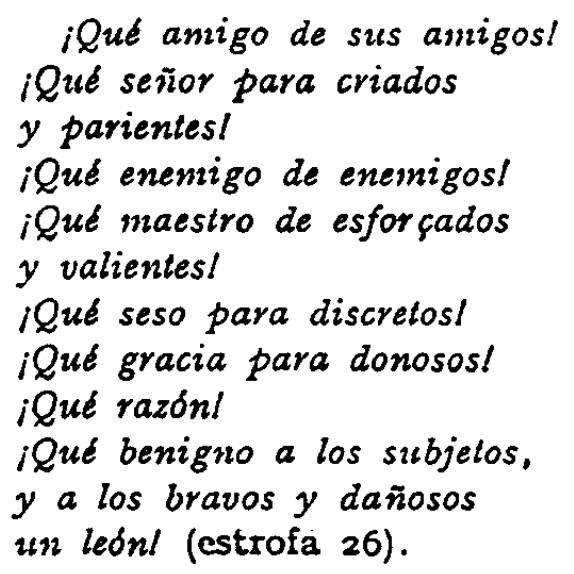

Siguen las dos estrofas más discutidas de la Coplas, pues varios críticos han encontrado muy prolija la enumeración de imperatores de la antigüedad ${ }^{3}$, a cada uno de los cuales se le considera, de acuerdo con la Crónica general de don Alfonso el Sabio 4, muy eminente en una virtud que era poseída en el mismo grado por don Rodrigo, lo que en algunas de ellas incluso está documentado 5 . Tales censuras nacen de olvidar que la fama, vida intermedia entre la mortal y perecedera y

1 Véanse las pp. 185-I89 de SERRANo DE HARO.

2 F. GARcf LORCA, Obras completas, Madrid, I954, p. 467: "Qué gran tovero en la plazal / iQué buen serrano en la sierral / IQué blando con las espigas! / 1Que duro con las espuelas/ / Qué tierno con el rocio! / iQué deslumbrante en la feria! / lQue tremendo con las últimas / banderillas de tinieblal.

3 M. Mentindez y Pelayo, Obras completas, t. XVIII, Madrid, I944, p. 408, I A. CORTINA, ed. cit., p. LXIV.

- E. R. CuRTius, Jorge Manrique und der Kaisergedanke, en $Z R P h$, I932, LII, pp. I29-52.

- Sobre la prudencia, fortaleza y liberalidad del conde de Paredes véase su retrato en los Claros varones de Castilla de F. DEL, PULGaR, ed. de J. DomínCUIZ BORDONA, Madrid, I942, pp. 90-95. Sobre su liberalidad debe verse también lo que dice a los reyes en su testamento, en el que pide 300.000 maravedies para poder cumplir las obligaciones de su conciencia, p. 93 de SERRANO DE HARO; de su religiosidad puede dar testimonio la carta que a la hora de su muerte escribíb a los re yes, pp. 226-227 de este mismo autor. 
la que verdaderamente es eterna, es la propia de los héroes antiguos, a quien aquella época no créa capaces de haber alcanzado la salvación ${ }^{1}$. También el deseo de coleccionar bustos y esculturas de cuerpo entero, ya sentido entre nosotros por don Alfonso V el Magnánimo, servia indirectamente para subrayar lo ejemplar y arquetípico de tales figuras, lo que lo mismo justifica estéticamente la galería de Manrique que el posterior gusto plateresco por medallones con cabezas de hombres ilustres que se ven en la fachada del Ayuntamiento de Sevilla, en el claustro del Colegio del Arzobispo de Salamanca o en el monasterio de Lupiana.

I a tercera parte del poema, que es el descenso de la ojiva, termina con la venida de la Muerte y con su diálogo con el caballero. Esta Muerte, que aparece al final de una estrofa cuyos tres después nos llevan hasta el último triunfo de don Rodrigo, no tiene aspecto macabro ni repelente, pues no se trata de la muerte en abstracto, sino de la propia y particular del conde de Paredes, de la buena muerte que él había merecido con sus buenas obras. Incluso se diría que los cuatro posesivos de esta estrofa, pero sobre todo los del verso anterior y posterior de aquél en que se nombra a la Muerte, irradian su acción sobre ella, haciéndola más suya:

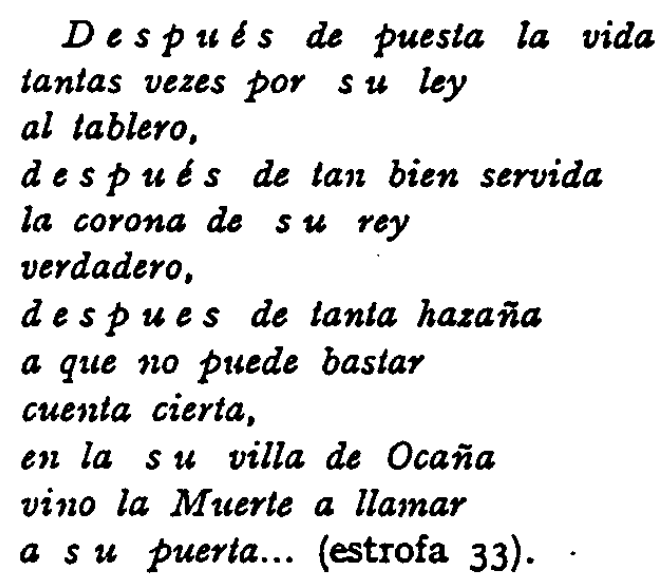

Ya hizo notar Anna Krause 2 "el abrupto cambio de tono" 3 que marca el paso de la segunda a la tercera parte del poema y que use acentúa más cuanto más nos vamos acercando al fin, pues la serena dignidad

2 Sobre la importancia de la fama para los caballeros de aquella época y su relación con el recuerdo de los héroes antiguos debe consultarse $M$. R. LIDA, La Idea de la Fama en la Edad Media Castellana, México, 1952.

2 A. Krause, Jorge Manrique and the Cult of Death in the Cuatrocientos, 'Publications of the University of California at Los Angeles in Languages and Literatures', vol. I, núm. 3, pp. 79-I76, Berkeley, California, r937.

$s$ As I observed earlier, an abrupt change of mood marks the transition from the second to the final movement of the composition... (Op. cit., p. I24). 
con que el poeta comienza el elogio de Rodrigo Manrique se convierte en un alegre canto de alabanza conforme, inspirado por el orgullo familiar y por el patriotismo, exalta las hazañas y virtucles de su padre. Estos acentos triunfales se mantienen en las últimas estrofas, en las que acepta Rodrigo Manrique el desafío final y pasa al reino de la gloria. De este modo el poema, que había empezado en tono elegíaco y plañidero, termina con una victoriosa afirmación, como si el poeta se estuviera esforzando por actualizar las famosas palabras de S. Pablo: 'Porque cuando este ser corruptible se haya vestido de incorruptibilidad y este ser mortal se haya revestido de inmortalidad, entonces se cumplirá 1o que está escrito: La muerte fue absorbida por la victoria' (I Corintios, XV, 54)" '. Por eso no debe extrañarnos que la Muerte aparezca aquí, para usar las palabras de la misma Anna Krause, como uel benévolo consejero, como el ángel guardián que prepara al maestre para su jornada hacia el más allán ${ }^{2}$. Esto se ve mejor al estudiar la fuente inmediata de tales estrofas, que es el diálogo sobre la muerte de Santillana de su capellán Pero Díaz de Toledo, con el que tienen muy elocuentes coincidencias verbales ${ }^{3}$. Menos directo es el influjo del "Tratado consolatorio" del marqués de Villena, quien también sostiene que la "muerte,

1 "The modulation becoming accentuated as the movement advances. The calm dignity with which the poet beging his eulogy of Rodrigo Manrique becomes a paean of praise as the poet, inspired by family pride and patriotism, exalts the achievements and character of his father. This triumphant note is sustained throughout the closing stanzas, in wich Rodrigo Manrique accepts the final call with stoic fortitude and passes to 'the realu of glory'. Thus the poem which had begun in plaintive elegiac strain closes in a note of victorious affirmation as though the poet were seeking to actualize the famous words of St. Paul: 'So when this corruptible shall have put on incorruption, and this mortal shall have put on inmortality, then shall be brought to pass the saying that is written, Death is swallowed up in victory." (Op. cit., pp. 124-125.)

2 "The benevolent counselor, the guardian angel, who prepares the Haestre for his journey to the realm beyond" (Op. cit., p. Ir3.)

3 "Agora que Nuestro Señor vos quiere visitar non fallezca vuestra virtud e esfuerço... E viestra clara virtud non fallezca en el rigor del trabajo... Desatado este cuerpo mortal, el ánima se va a dar cuenta a aquél a quien la crión.... dice el capellán. Y responde el marqués: "Encomiendo mi alma a Dios, que la crió e redimió, e fago fin de mi vida derramando lágrimas de mis ojos, e gimiendo demando a Dios misericordia e piedad, e con el rey David digo: Confieso mi justicia e pecado a ti, Dios mio, y tú perdonarás la impiedad e maldad mia. E suplicote que pongas la tu pasión entre mi e el juizio tuyo, e espirando digo: Domine Jhesu, suscipe spiritum metum. In manus tuas, Domine, commendo spiritum meum.n Is Dialogo e razonamiento en la muerte del marqués de Santillana de PERO DLAZ DE TOLEDO puede lecrse en Opísculos literarios de los siglos XIV a XVI, ed. A. PAZ y Meisia, Madrid, I892, pp. 247-360. 
en ciertas circunstancias, debe ser considerada un bien; que el verdadero cristiano debe enfrentarse con ella con esperanza y aun con alegria, absteniéndose de las violentas manifestaciones de dolor personal a que los griegos solían entregarsen ${ }^{1}$. Lo que demuestra que la actitud de nuestro poeta es la general entre los escritores del siglo xv.

Comienza la Muerte, como demuestra Gilman en su fino análisis de estas estrofas ${ }^{2}$, por apelar a la fortaleza del caballero, con más precisión podríamos decir "a su fortaleza de caballero", muy hecho a arriesgar su vida y salud por la honra y la fama, que es el primer señuelo que le muestra, incitándole a tensar su virtud, es decir, su valor para afrontar el trance que le aguarda, que debe endulzar el convencimiento de que su recuerdo quedará vivo:

\author{
No se os faga tan amarga \\ la batalla temerosa \\ que esperdis, \\ pues olra vida más larga, \\ de fama tan gloriosa \\ acd dexdis... (estrofa 35).
}

Lo que hay en estos versos y en los anteriores de desafío, aunque retórico, al valor del maestre, es lo que ha hecho a Gilman suponer que la Muerte aparece en figura de caballero ${ }^{3}$. Aunque no osamos afirmarlo nosotros, resulta evidente que esta Muerte es distinta del descarnado esqueleto de las danzas; en vez de burlarse de su víctima, la Muerte exhorta a don Rodrigo con la elocuencia del predicador que ayuda a bien morir, pues después de ofrecerle como consuelo la supervivencia de su recuerdo, se eleva a más altas consideraciones, afirmando que

\footnotetext{
Aunque esta vida de onor

tampoco no es eternal

ni verdadera.

mas con todo es muy mejor

que la otra temporal

perescedera... (estrofa 35 ).
}

1 "Its basic teuets were that death under certain circumstances should be considered a good, that the true Christian should face death with hope and even joy, refraining from the violent manifestations of personal grief indulged in by the Greels." (A. KRAUSE, OP. cit, p. II5.)

2 S. Grinan, Tres retratos de la muerte en las "Coplaso de Jorge Manrique, en NRFH, 1959. XIII, pp. 305-324.

- Op. cit., p. 310. 
Lo que prepara al moribundo para la idea de que la vida eterna es la que se gana sirviendo a Dios, cada uno dentro de su estado, como él habia hecho al participar en la guerra contra los moros:

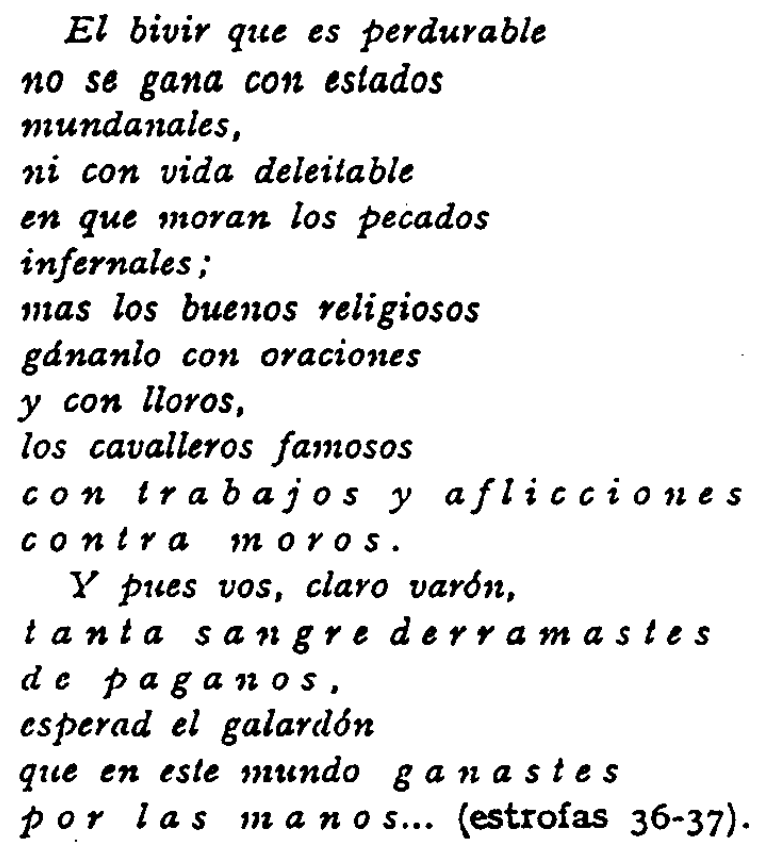

Es muy curioso que la afirmación de que la guerra divinal es camino seguro de salvación, no se tiemple, como en El conde Lucanor, con ninguna alusión a las disposiciones interiores que eran necesarias para que sobrenaturalmente fuera fecunda ${ }^{1}$. Si coincide Jorge Manrique con don Juan Manuel en creer que tal guerra es el modo específico de alcanzar la vida perdurable los caballeros ${ }^{2}$, que, como los demás cristianos,

1Ca si allí muriesse, pues habia fecho la emienda que pidiera ante que de su tierra se partiesse, et estaba en verdadera penitencia, que era cierto quel' habría Dios merced al alma, et que, si los moros fuessen vencidos, que tomaria Dios mucho servicio et serian todos muy de buena ventura." ( $E l$ conde Lucanor, ed. de P. HENRiguez UREÑA, Buenos Aires, I939, p. 34.) "Ca si en la guerra de los moros morierdes estando en verdadera penit e n c i a sodes mártir et muy bienaventurado, et aunque por armas non murades, las buenas obras et la buena entención vos salvará." (El conde Lucanor, ed. cit., p. I54.)

2 "Et vos, señor conde Lucanor, pues sabedes que la vuestra caça et la vuestra honra et todo vuestro bien paral cuerpo et paral alma es que fagades servicio a Dios, et sabedes que en cosa del munclo, s e gund el vu est r o es t a do, non le podedes tanto servir como en haber guerra con los moros para ensalçar la sancta et verdadera fe católica, conséjovos yo que, luego que podades seer seguro de las otras partes, que hayades guerra con los moros... Et pues a los señores vos es bueno et aprovechoso haber algund wester, cierto es que de los mes- 
solo triunfan de la Muerte aceptándola de pleno grado, como aquí el maestre, que corona todas sus victorias con esta victoria, en la que tanto brilla su fortaleza como su piedad. Los tres adjetivos que califican su consentimiento son prueba elocuente de la importancia de su aceptación. Solo queda al conde encomendarse a Aquél por cuya mediación puede el hombre salvarse, lo que hace en versos cuyo equilibrio entre lo que el poeta quiere decir y los recursos con que cuenta el idioma es aún mayor que en los demás, por lo que resultan más lapidarios:

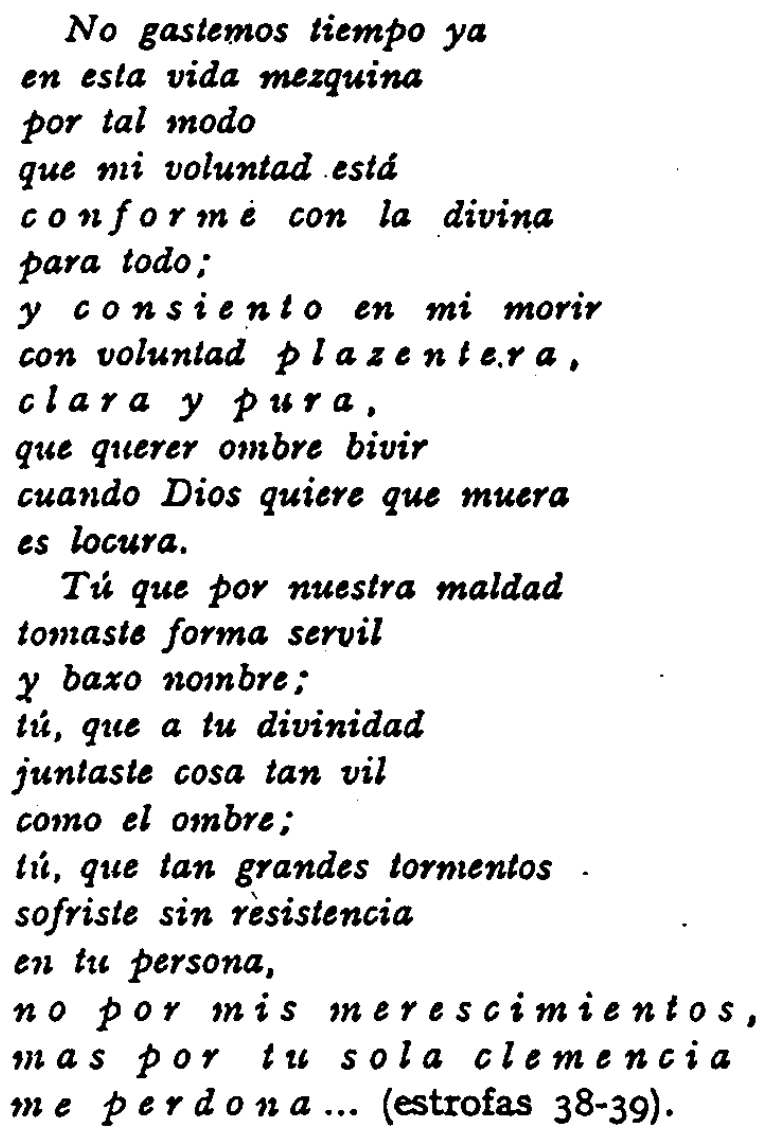

Después de que don Rodrigo vence a la Muerte al aceptar la propia, la que él se habla ganado peleando contra los moros, después de la humildad con que reconoce sus escasos méritos y se encomienda a la misericordia del Redentor, encontramos de nuevo en la última estrofa el tono objetivo y en este caso casi notarial con que se nos cuenta su tránsito, matizado por una nota de orgullosa satisfacción que levemente riza la impasibilidad de nuestro poeta:

teres non podedes haber ninguno tan bueno et tan lionrado et tan a pro del alma et del cuerpo, e tan sin daño, como la guerra de los moros.n (El conde Lucanor, ed. cit., pp. I53-154.) 


\section{... y aunque la vida murió \\ nos dexó harto consuelo \\ su memoria (estrofa 40).}

Hemos visto cómo estas Coplas, en que tradicionalmente se veía la fusión del otoño de la Edad Media con los primeros efluvios del Renacimiento, deben a la primera la estructura fuertemente dialéctica de la meditación sobre nuestro destino, en la que abundan los nexos lógicos, escasean los adjetivos, se emplean formas verbales e interrogaciones y exclamaciones de valor docente y se hace un uso muy didáctico de los paralelismos y las anáforas; al nominalismo deben las Coplas su exaltación de lo sensible, que lleva al poeta a limitarse a las caídas que todos vieron, da a sus evocaciones de lo concreto un valor casi táctil y le inclina hacia las imágenes que reflejan su experiencia; el platonismo del Renacimiento nos explica a su vez la idealización del conde de Paredes, de cuya vida se silencian los hechos de dudosa ejemplaridad, cuyas virtudes son comparadas con las de claros varones celebrados por la misma Roma y cuya muerte es el paradigma de la del cristiano, que lia de aceptarla voluntariamente, como Cristo lo hizo. 'También son rasgos renacentistas la serenidad, el equilibrio entre el fondo y la forma y el lenguaje, aunque elevado, accesible a todos por la ausencia de esos latinismos léxicos y sintácticos que tanto abundan en los poetas de la época de Juan II ${ }^{1}$.

\section{ENRIQUe Moreno BÁEZ}

1 Este trabajo ha sido escrito con ayuda del Crédito para el Fomento de la Investigación en la Universidad. 